\title{
Habilidades sociais e análise do comportamento: compatibilidades e dissensões conceitual-metodológicas
}

Social skills and behavioral analysis: compatibilities and conceptual and methodological divergences

Habilidades sociales y de análisis del comportamiento: la compatibilidad y la discordancia conceptual y metodológica

\author{
Alessandra Turini Bolsoni-Silva* \\ Kester Carrara ${ }^{* *}$
}

\begin{abstract}
Resumo
Habilidades sociais podem ser conceituadas como conjunto de comportamentos emitidos diante das demandas de uma situação interpessoal, desde que maximizem os ganhos e reduzam as perdas para as interações sociais. Ainda que haja a descrição geral de habilidades sociais, populações específicas têm necessidades interpessoais próprias. O mapeamento delas e consequentes intervenções focadas parece ser um caminho produtivo no que se refere ao estudo das habilidades sociais. A análise comportamental aplicada entende que o repertório das pessoas deva ser avaliado o mais completamente possível, considerando suas influências filogenéticas, ontogenéticas e culturais. Acredita-se que parte significativa dos "problemas comportamentais" é mantida pela produção de reforçadores positivos e negativos, requerendo, para o seu entendimento, a avaliação desse repertório. Esse trabalho discute a possibilidade de descrever funcionalmente habilidades sociais, verificando a tese de entendê-las como adjetivação de um repertório que possa ser incompatível com comportamentos-problema. Para tanto, define-se habilidades sociais e análise funcional, para, na sequência, tecer considerações sobre as relações entre esses conceitos, com base em exemplos empíricos.
\end{abstract}

Palavras-chave: habilidades sociais; análise do comportamento; análise funcional.

Pós-doutora pela Faculdade de Medicina, professora do Programa de Pós-graduação em Psicologia do Desenvolvimento e Aprendizagem da Universidade Estadual Paulista Júlio de Mesquita Filho (Unesp), bolsista de produtividade do CNPq. E-mail: bolsoni@fc.unesp.br.

** Livre-docente pela Universidade Estadual Paulista Júlio de Mesquita Filho, professor adjunto do Departamento de Psicologia da Faculdade de Ciências da Unesp, bolsista de produtividade do CNPq. E-mail: kester@fc.unesp.br. 


\section{Abstract}

Social skills can be conceptualized as a set of different kinds of behavior in the face of demands in an interpersonal situation, provided they maximize gains and reduce losses to social interactions. While there is a general description of social skills, specific populations have their own interpersonal needs. Their mapping and consequent focused interventions appear to be a productive way in what concerns the study of social skills. According to the Applied Behavior Analysis, the persons' repertoire should be assessed as completely as possible, considering its phylogenetic, ontogenetic and cultural influences. It is believed that a significant proportion of "behavioral problems" is maintained by the production of positive and negative reinforcement, its understanding requiring the assessment of that repertoire. This paper discusses the possibility of describing social skills functionally, testing the argument of understanding them as adjectives that qualify a directory eventually incompatible with problematic behavior. For such, one must define social skills and functional analysis, so as to consider, subsequently, the relations between these concepts, based on empirical examples.

Key-words: social skills; behavioral analysis; functional analysis.

\section{Resumen}

Las habilidades sociales se pueden conceptualizar como un conjunto de conductas emitidas ante las demandas de una situación interpersonal, siempre que se maximizan las ganancias y se minimizan las pérdidas en las interacciones sociales. Si bien no es una descripción general de las habilidades sociales, puesto que cada población tiene sus propias necesidades interpersonales. La asignación de estas intervenciones y el enfoque consecuente parece ser una manera productiva en lo que respecta al estudio de las habilidades sociales. El análisis aplicado del comportamiento considera que el repertorio de personas debe ser evaluado de la forma más completa posible, teniendo en cuenta sus influencias filogenéticos, ontogénicos y culturales. Se cree que una proporción significativa de los "problemas de conducta" se mantiene debido a la producción de reforzadores positivos y negativos que requieren, para su comprensión, la evaluación del repertorio. Este artículo presenta la posibilidad de describir funcionalmente las habilidades sociales, verificando la teoría de entenderlas como adjetivos que describen un repertorio que puede ser incompatible con los problemas de conducta. Para ello, definimos las habilidades sociales y el análisis funcional, para poder, en secuencia, tejer consideraciones sobre las relaciones entre estos conceptos a partir de ejemplos empíricos.

Palabras clave: habilidades sociales; análisis de comportamiento; el análisis funcional. 
objetivo deste trabalho é discutir a possibilidade de descrever funcionalmente habilidades sociais, verificando a tese de entendê-las como adjetivação que se refere a repertórios que, ao serem promovidos, podem reduzir comportamentos que trazem prejuízo para as pessoas, quanto à obtenção de reforçadores. Para tanto, faz-se necessário, num primeiro momento, definir habilidades sociais e análise funcional (contextualizada no behaviorismo radical), para, na sequência, tecer consideraçóes sobre as relaçôes entre esses conceitos, com base em exemplos empíricos. Os conceitos apresentados foram selecionados desde a literatura de habilidades sociais, de análise do comportamento aplicada e de estudos empíricos que, explícita ou implicitamente, testaram relações entre problemas/transtornos e repertório de habilidades sociais.

\section{Habilidades sociais: conceituação e caracterização}

O termo habilidades sociais (HS) remete ao campo teórico-prático do treinamento de habilidades sociais (THS) já amplamente caracterizado por Del Prette e Del Prette (1999; 2001), que realizaram extensa revisão da literatura, apresentaram taxonomias e definições, explicitaram influências de abordagens teóricas e implicaçôes para a pesquisa e intervenção na área.

O movimento do THS teria sido iniciado por Salter (1949), retomando os achados de Pavlov acerca do reflexo condicionado, o que lhe permitiu promover técnicas para aumentar a expressividade verbal e facial. Wolpe (1958) ampliou e especificou o repertório de HS identificando a possibilidade de avaliar e intervir em comportamentos envolvidos na expressão de sentimentos negativos e na defesa dos próprios direitos, o que denominou de assertividade. Lazarus (1977) trabalhou com Wolpe e criticou a ênfase exagerada na expressão de sentimentos negativos e propôs, então, a inclusão da expressão de sentimentos positivos (Del Prette \& Del Prette, 1999).

No cenário atual, Caballo (1996) apresenta uma articulação conceitual entre habilidades sociais e expressão de atitudes, sentimentos, opiniōes e desejos, enfatizando o respeito a si próprio e aos outros, existindo, em geral, resolução dos problemas imediatos da situação e diminuição da probabilidade de problemas futuros.

Del Prette e Del Prette (1999) concordam que assertividade envolveria a expressão apropriada de sentimentos negativos e a defesa dos próprios direitos, e que uma pessoa socialmente habilidosa também deveria apresentar habilidades de comunicação, de resolução de problemas interpessoais, de cooperação e de desempenhos nas atividades profissionais. A taxonomia 
das habilidades sociais é ampliada pelos mesmos autores (2001), que as organizaram em categorias: (a) habilidades sociais de comunicação: fazer e responder a perguntas; gratificar e elogiar; pedir e dar feedback nas relações sociais; iniciar, manter e encerrar conversação; (b) habilidades sociais de civilidade: dizer "por favor"; agradecer; apresentar-se; cumprimentar; despedir-se; (c) habilidades sociais assertivas de enfrentamento: manifestar opinião, concordar, discordar; fazer, aceitar e recusar pedidos; desculparse e admitir falhas; estabelecer relacionamento afetivo/sexual; encerrar relacionamento; expressar raiva e pedir mudança de comportamento; interagir com autoridades; lidar com críticas; (d) habilidades sociais empáticas: parafrasear, refletir sentimentos e expressar apoio; (e) habilidades sociais de trabalho: coordenar grupo; falar em público; resolver problemas, tomar decisões e mediar conflitos; habilidades sociais educativas; e (f) habilidades sociais de expressão de sentimento positivo: fazer amizade; expressar solidariedade e cultivar o amor.

De todo modo, classificar as HS em categorias não é o mesmo que defini-las, o que não constitui tarefa simples, como se observa pela ausência de consenso na literatura. A título de exemplificação são citados alguns autores no que tange a definições de HS. MacKay (1988) critica a definição sobre HS de Alberti e Emmons (1970), a qual enfocaria mais o comportamento da pessoa que as consequências positivas da interação. Alberti e Emmons (1978) parecem ter revisado a definição de 1970, atribuindo maior importância às consequências obtidas diante de respostas sociais assertivas, não assertivas e agressivas. Assim, assertividade seria o processo pelo qual o indivíduo (emissor) expressaria, de forma adequada, sentimentos e pensamentos, ou seja, utilizando entonação, latência e fluência de fala apropriadas, ouvindo o receptor para, então, responder, de forma a atingir seus objetivos sem prejudicar as relaçôes futuras com este (Alberti \& Emmons, 1978; Caballo, 1987), no caso, a expressão de sentimentos negativos e defesa dos próprios direitos. Não assertividade ocorreria quando o emissor não expressa seus sentimentos, seus pensamentos ao receptor, emitindo, muitas vezes, comportamentos contra a própria vontade ou deixando de defender-se por medo de prejudicar sua relação futura com o receptor, e, por isso, muitas vezes o emissor é explorado e prejudicado, sem, contudo, atingir seus objetivos. A agressividade, às vezes, permite atingir os objetivos desejados, mas, no processo, magoa os demais, fazendo escolhas por eles, além de desvalorizálos como pessoas, possibilitando represálias futuras. Por outro lado, o comportamento assertivo permite a expressão honesta de seus sentimentos, 
geralmente atingindo os objetivos desejados, não prejudicando a si mesmo, nem ao receptor.

Caballo (1991) apresenta uma definição que explicita um maior número de habilidades, afirmando que comportamento socialmente habilidoso ou mais adequado refere-se à expressão, pelo indivíduo, de atitudes, sentimentos, opinióes, desejos, respeitando a si próprio e aos outros, existindo, em geral, resolução dos problemas imediatos da situação e diminuição da probabilidade de problemas futuros.

Parece necessário adotar alguma definição e avaliar consequências dessa decisão. Nesse sentido, revela-se pertinente o encaminhamento dado por Del Prette e Del Prette (1999), segundo os quais habilidades sociais podem ser caracterizadas como conjunto de comportamentos emitidos pelo indivíduo diante das demandas de uma situação interpessoal na qual se maximizem os ganhos e se reduzam as perdas para as pessoas envolvidas numa interação social. Todos os autores descrevem comportamentos que parecem maximizar a obtenção de reforçadores sociais (Bolsoni-Silva, 2002), no entanto os autores contemporâneos, como Caballo (1991) e Del Prette e Del Prette (1999), ampliam o conjunto de comportamentos avaliados para além dos de assertividade, correspondentes à expressão de sentimentos negativos e defesa dos próprios direitos. Por essa razão, tem-se optado por usar o termo habilidoso a assertivo.

Nessa perspectiva, Bolsoni-Silva et alii (2006) revisaram artigos brasileiros em habilidades sociais e constataram que: (a) em sua maioria, estes se preocupam em caracterizar determinadas populaçôes, tais como pais, universitários e crianças; (b) em menor número, descrevem e testam propriedades psicométricas de instrumentos de avaliação; e (c) alguns avaliam a efetividade de procedimentos de intervenção. Ainda que não seja o foco deste texto descrever taxonomias específicas, conclui-se que, ainda que exista uma descrição geral de habilidades sociais a serem foco de intervençôes e de pesquisas (Del Prette \& Del Prette, 2001), populações específicas têm necessidades interpessoais próprias, de modo que seu mapeamento e consequentes intervenções focadas parecem constituir um caminho produtivo para fazer avançar o programa de pesquisa em habilidades sociais. Tal movimento já foi iniciado (Bolsoni-Silva et alii, 2006), mas necessita de ampliação, o que vem justificando o grande número de estudos de caracterização em habilidades sociais (por exemplo, Bolsoni-Silva \& Marturano, 2008; Cecconelo \& Koller, 2000; Del Prette \& Del Prette, 2002; Santana, Otto \& Bastos, 1993). Essas pesquisas também têm servido de subsídio para a elaboração e teste de novos instrumentos de avaliação e têm dado suporte a pesquisas de intervenção. 
Como exemplo, pode-se afirmar, no caso das interações específicas entre pais e filhos, que as habilidades sociais costumeiramente mais relevantes envolvem: (a) comunicação, expressividade e enfrentamento (expressar sentimentos positivos, negativos e opiniōes, demonstrar carinho, brincar com o filho) por terem sido mais frequentemente relatadas por pais com filhos sem problemas de comportamento; (b) estabelecimento de limites (identificar e "consequenciar" comportamentos socialmente habilidosos e não habilidosos, estabelecer regras e "consequenciar" o seguir regras de maneira consistente, cumprir promessas, identificar erros e pedir desculpas), que são comportamentos mais frequentes em crianças sem problemas de comportamento (Alvarenga \& Piccinini, 2001; Bolsoni-Silva, 2008; Bolsoni-Silva \& Marturano; 2007; 2008; Cia, Pereira, Del Prette \& Del Prette, 2006; Leme, 2008; Boas, 2007).

Para avaliação e intervenção com universitários, as habilidades sociais que se mostram mais relevantes para investigação e análise são: (a) falar em público (apresentação de seminários, responder a perguntas do professor, fazer comentários ou dar recados em sala de aula, falar com autoridade, reclamar com o professor sobre notas e avaliações, trabalhar em grupo: ouvir, concordar/ discordar, lidar com críticas, negociar, argumentar, perguntar, responder a perguntas). Assim, explicita-se negociar enquanto um comportamento na interação social em que ambos os interlocutores precisarão expressar suas opiniōes sobre determinado assunto ou problema e então ambos cederem em algo, de forma a encontrar uma solução que agrade aos dois; (b) lidar com relacionamentos amorosos; aproximar-se de alguém para relação amorosa, manter ou terminar relacionamentos (Boas, Silveira \& Bolsoni-Silva, 2005; Del Prette \& Del Prette, 2003; Del Prette et alii, 2004; Del Prette, Del Prette \& Barreto, 1999); e (c) interagir com familiares: expressar afeto, lidar com críticas, comunicar-se (Bandeira \& Quaglia, 2005).

Já as crianças precisariam, segundo Caldarella e Merrell (1997), apresentar: (a) habilidades acadêmicas (tirar dúvidas, seguir as orientações do professor, saber trabalhar de forma independente); (b) habilidades de autocontrole (controlar o humor, negociar, lidar com críticas); (c) habilidades de relacionamentos com pares (cumprimentar, elogiar, oferecer ajuda, convidar os colegas para brincar); (d) habilidades de ajustamento (atender a pedidos; seguir regras e instruçoes, usar tempo livre de forma apropriada); (e) habilidades assertivas (responder a cumprimentos, iniciar conversação, aceitar e recusar convites). Del Prette e Del Prette (2006) reiteraram a relevância das habilidades sociais acadêmicas, de autocontrole e expressividade emocional, solução de problemas interpessoais, habilidades para fazer amizades, civilidade, empatia e assertividade. 
Ainda em relação às crianças, Bolsoni-Silva, Marturano e Loureiro (2009), para validar um instrumento de habilidades sociais para pré-escolares, identificaram e avaliaram um conjunto dessas habilidades que foram mais frequentes para as crianças indicadas pelos professores como sendo socialmente habilidosas e não apresentando indicativos de problemas de comportamento. Foram encontrados três fatores: (a) fator sociabilidade: têm relações positivas, mostram interesse pelos outros, fazem amigos, expressam frustração e desagrado de forma adequada, comunicam-se positivamente, expressam desejos, expressam direitos, expressam carinhos, brincam com colegas, usualmente estão de bom humor, fazem elogios, cumprimentam, interagem de forma não verbal, participam de grupos; (b) fator iniciativa: tomam a palavra, expressam opiniōes, participam de temas de discussão, tomam iniciativas, negociam e convencem, prestam ajuda; (c) fator busca de suporte: procuram atenção, fazem pedidos e perguntam.

Nas interações sociais, porém, nem sempre as pessoas emitem comportamentos tal como descritos até o momento, o que parece justificar a proposição de Del Prette e Del Prette (2001) das seguintes definições para formas de interagir socialmente:

[...] [reação] habilidosa (que demonstra assertividade, empatia, expressão de sentimentos positivos ou negativos de forma apropriada, civilidade, etc.), [reação] não habilidosa passiva (que demonstra esquiva ou fuga ao invés de enfrentamento da situação) e [reação] não habilidosa ativa (que demonstra agressividade, negativismo, ironia, autoritarismo, etc.) (Del Prette \& Del Prette, 2001, p. 65).

Nesse caso, a definição inclui padrões para obter sucesso e também os que podem levar a problemas interpessoais.

Outro conceito importante e também controverso é o de competência social (CS), muitas vezes usado como sinônimo de HS. Para alguns autores, a expressão "competência social" é usada em um sentido avaliativo, visando a qualificar o nível de proficiência com que os comportamentos são ou deveriam ser emitidos (McFall, 1982 e Del Prette \& Del Prette, 1996).

Nas palavras de Del Prette e Del Prette (2001):

[...] Defendemos a ideia de que as pessoas socialmente competentes são as que contribuem na maximização de ganhos e na minimização de perdas para si e para aquelas com 
quem interagem [...] o desempenho socialmente competente é aquele que expressa uma leitura adequada do ambiente social, que decodifica corretamente os desempenhos esperados, valorizados e efetivos para o indivíduo em sua relação com os demais (Del Prette \& Del Prette, 2001, p. 33).

Quanto às abordagens teóricas, pode-se afirmar a partir de Del Prette e Del Prette (1999) que houve influência de autores de diferentes orientaçóes teóricas, sendo destacados cinco modelos que permitiram sua estruturação: o cognitivo, o da teoria de papéis, o da assertividade, o da aprendizagem social e o da percepção social. Bolsoni-Silva (2002) defende que cada um desses modelos possa ser entendido à luz da análise do comportamento: (a) o modelo cognitivo e o de percepção social são teorias que atentam para a relevância de incluir eventos privados nas análises realizadas; (b) a teoria dos papéis indica o papel plástico do comportamento, em que deve haver flexibilidade em assumir diferentes papéis sociais; (c) o modelo da assertividade descreve comportamentos respondentes e operantes, os quais são claramente conceituados pela análise do comportamento; (d) o modelo de aprendizagem social remete à relevância da observação, que, para Catania (1999/1998), tem, inclusive, influência filogenética. Por outro lado, o autor afirma que quaisquer comportamentos são mantidos sobretudo por suas consequências. A autora acredita que quanto mais socialmente habilidosa, maior a probabilidade de obter reforçadores e, por consequência, ampliar repertório comportamental, favorecendo lidar com situações de conflito que claramente envolvem estimulação aversiva. Strapasson, Carrara e Lopes Júnior (2007) acreditam que cabe aos analistas do comportamento, enquanto programa de pesquisa, o esforço de interpretar termos de outras teorias. Bolsoni-Silva (2002) iniciou uma reflexão sobre habilidades sociais e análise do comportamento sem, contudo, aprofundá-la, sobretudo no que se refere ao termo análise funcional, sendo que um dos aspectos para essa dificuldade é a falta de consenso entre as definiçôes de habilidades sociais e de competência social.

\section{Behaviorismo radical, análise funcional e habilidades sociais}

Tal como as HS, a expressão "análise funcional” também tem variações (Meyer, 2001) e foi elaborada com base na análise experimental do comportamento (AEC). A AEC descreve leis do comportamento subsidiadas por dados obtidos com a manipulação de variáveis em situações de pesquisa controladas (como a situação típica de laboratório). Tal conceituação pode ser frequentemente encontrada em muitos textos de Skinner, como, por 
exemplo, em Ciência e comportamento humano (Skinner, 1953/1993). O conceito de análise funcional mais referenciado remete a essa obra:

[...] As variáveis externas, das quais o comportamento éfunção, dão margem ao que pode ser chamado de análise causal ou funcional. Tentamos prever e controlar o comportamento de um organismo individual. Essa é a nossa "variável dependente" - o efeito para o qual procuramos a causa. Nossas "variáveis independentes" - as causas do comportamento - são as condiçōes externas das quais o comportamento é função (Skinner, 1953/1993, p. 45).

Entretanto, tais conceitos foram utilizados por Skinner (1992/1957, 1993/1974, 1953/1993) para interpretar diversas áreas aplicadas, além do contexto de laboratório, como educação, clínica, política e religião, inclusive indicando o comportamento verbal como passível de descrição e de análise em Verbal Behavior (Skinner, 1992/1957), ainda que não tivesse anunciado claramente metodologias específicas para o estudo de tais fenômenos.

Carrara (2008) sugere uma forma de organização das possibilidades de atuação do analista do comportamento em: (a) análise experimental do comportamento, que prioriza, como estratégia metodológica de pesquisa, o delineamento de sujeito único e testa empiricamente variáveis dependentes e independentes; (b) análise conceitual do comportamento, que abrange investigações teóricas, filosóficas e epistemológico-metodológicas; (c) análise aplicada do comportamento, que comporta intervenção individual e social e inclui, por exemplo, pesquisas em situação clínica, organizações e comunidades.

Nessa perspectiva, todas as dimensões da análise do comportamento privilegiam a análise funcional. $\mathrm{Na}$ área clínica ou outras áreas aplicadas, Mayer (1999) busca usar tecnologia de avaliação e de intervenção a partir do modelo construcional de Goldiamond (1974/2002) que são concordantes com a filosofia behaviorista radical, a qual entende todo comportamento como fruto de três níveis de seleção: filogenético (história da espécie), ontogenético (história particular do indivíduo) e cultural (história das práticas culturais) (Skinner, 1984).

A filosofia que certamente influenciou o pensamento de Skinner, na dimensão ética, foi a do pragmatismo (Abib, 2001a), a qual, por sua vez, foi influenciada por Darwin, entendendo que há ação e consequência. Nessa perspectiva, Skinner propõe uma teoria do comportamento que pode ser denominada como interacionista (Abib, 1993) e consequencialista (Abib, 
2004), uma vez que são as consequências reforçadoras que selecionam o comportamento operante. Skinner (1974) define comportamento operante enquanto aquele que especifica ao menos uma relação entre resposta e consequências. As consequências podem aumentar (reforçadoras) ou reduzir (punidoras) sua probabilidade de ocorrência.

Tal seleção ocorre também no âmbito das práticas culturais. Para Baum (1999), a evolução cultural altera o comportamento social de um grupo, possivelmente por trazer consequências reforçadoras comuns a esse grupo e não necessariamente para os indivíduos de forma particular; cultura implicaria, portanto, comportamento verbal e não verbal adquirido na interação com determinado grupo. Abib (2004) afirma que o comportamento operante está na origem de práticas que produzem consequências de sobrevivência cultural, pois uma pessoa pode emitir respostas diferentes das do grupo e, então, tal comportamento pode produzir as mesmas consequências reforçadoras para as pessoas que o imitarem. Práticas culturais sugerem - ato contínuo - consequências que as mantêm. Isso implica, para Abib (2001b), que as sociedades planejem consequências específicas em prol da sobrevivência das culturas. Uma cultura pós-moderna requer controle do imediatismo da natureza e invenção de novas práticas culturais (Abib, 2001b).

Carrara (2005) ao analisar algumas questôes conceituais, cogita a possibilidade de utilização de metodologias alternativas, mas compatíveis com as propostas pela análise do comportamento, de forma a possibilitar o estudo da cultura. Tal posição também é destacada por Zamignani e Meyer (2007) que acreditam que, para o estudo de fenômenos envolvidos na clínica, há a necessidade de buscar novas metodologias.

Baum (1999) sugere uma estratégia de pesquisa especial, distinta do delineamento de sujeito único, para estudar o uso de batom por mulheres, ao afirmar “... essa mudança cultural só poderia ser medida estudandose muitas mulheres...” (p. 253); tal afirmação sugere a relevância do uso do comportamento verbal porque se refere a padrões comportamentais influenciados pela cultura, ou seja, passados de geração a geração pelo comportamento verbal. Outra conclusão possível, a partir de Baum (1999) é a possibilidade de trabalhar com populaçôes grandes, a fim de iniciar a descrição de características de certa prática cultural, podendo servir de base para tecer interpretações sobre metacontingências envolvidas nas práticas culturais.

Do ponto de vista de Andery, Micheletto e Sério (2005), Glenn 
(1986) define metacontingências como sendo contingências individuais entrelaçadas, que implicam, em longo prazo, a existência de um produto agregado, ou seja, algo que tenha valor de sobrevivência para a cultura, para além dos próprios indivíduos. Desse modo, o conceito de metacontingência tem sido discutido na análise do comportamento como uma unidade de análise para o estudo de práticas culturais.

Como exemplo, pode-se citar a interação social estabelecida entre pais e filhos: ambos têm histórias de aprendizagem, ontogenia e cultura próprias, porém se influenciam mutuamente. As relações ontogenéticas aí envolvidas podem ser denominadas de contingências entrelaçadas, pois respostas dos filhos constituem, a um só tempo, ocasião e consequência para respostas dos pais e vice-versa.

No que se refere ao terceiro nível de seleção, as práticas parentais positivas e negativas, que passam de geração a geração, também podem desencadear resultados adventícios. Tais resultados podem ser, respectivamente, pessoas socialmente habilidosas que sejam capazes de obter os reforçadores de que precisam sem, contudo, prejudicar outras pessoas, ou então pessoas com sérios problemas de comportamento, o que já é bastante referenciado na literatura científica (por exemplo, Patterson, Reid \& Dishion, 2002) e que pode ocasionar prejuízos para a cultura.

Mayer (1999) apresenta uma pesquisa que bem exemplifica, na literatura, mediante o uso de um delineamento de sujeito único, que os princípios do método construcional podem ser eficazes para promover comportamentos positivos, pois ao ensinar as crianças a seguir regras, houve a redução de problemas de comportamento, ainda que esses comportamentos não tenham sido foco de intervenção direta. Evans (1993) também acredita que avaliações e intervençôes devam mensurar, além dos comportamentos-problema, as potencialidades, recursos e suportes dos clientes/participantes. $\mathrm{O}$ repertório de habilidades sociais é, portanto, recurso a ser avaliado de forma a ampliá-las na superação de comportamentos problema.

Carr e Durang (1985), na mesma direção, encontraram, a partir de um delineamento experimental de sujeito único, que comunicação e comportamentos problema são topograficamente diferentes, mas podem ter a mesma função. Ao ensinarem as crianças a obterem atenção dos adultos pela comunicação verbal, observaram que seus problemas de comportamento reduziram de frequência.

No Brasil, também têm sido conduzidas pesquisas que buscaram descrever relações funcionais entre habilidades sociais e comportamentos-problema 
(Castro \& Bolsoni-Silva, 2008; Bolsoni-Silva \& Marturano, 2008). Estes trabalhos avaliam múltiplos comportamentos, comportamento social estabelecido entre pais e filhos, professor e aluno, terapeuta e cliente, ora se valendo de observação direta e ora de delineamento de grupo, por meio de instrumentos de relato verbal.

Castro e Bolsoni-Silva (2008), com base na observação em vídeo de duas professoras de pré-escolares, identificaram: (a) habilidades sociais de comunicação (dar atenção/ouvir atentamente o outro, manter contato visual, dar feedback positivo, iniciar e manter conversação, manter conversação trivial); (b) habilidades sociais de expressão de sentimentos positivos (sorrir e tocar); e (c) habilidades sociais de mediação de conflitos e empatia (oferecer ajuda, atender a pedidos, auxiliar em resolução de conflito). Em todos esses casos, essas habilidades sociais foram "consequenciadas" positivamente pelas crianças que retribuíam com atenção, comunicação, afeto, além de resolver os conflitos existentes com outros alunos. Adicionalmente, essas habilidades sociais ocorriam com baixa frequência em comparação com as práticas educativas negativas, sugerindo a influência cultural quanto a práticas coercitivas e também o déficit de habilidades sociais educativas contingentes a situaçôes que requerem repertório de autocontrole e de maior asserção.

Silveira (2009), também por meio de filmagem, identificou comportamentos do terapeuta correlacionados aos dos clientes, permitindo hipotetizar, enquanto função do comportamento, que, quanto mais o terapeuta concordava com o cliente e fazia interpretações das contingências em operação, mais o cliente era capaz de descrever contingências e relatar melhoras. Esses são elementos importantes tanto para a terapia comportamental quanto para a área das habilidades sociais.

As pesquisas de Bolsoni-Silva e Marturano (2007; 2008) permitiram diferenciar estatisticamente grupos (com e sem problemas de comportamento), quanto às habilidades sociais educativas parentais (HSE-P) que envolvem comunicação (iniciar e manter conversação, fazer perguntas, conversar acerca de sexualidade), expressividade (expressão de sentimentos positivos e negativos, expressão de opiniōes) e limites (concordar com cônjuge e cumprir promessas), indicando que esses comportamentos parentais podem constituir ambiente para promover habilidades sociais de seus filhos. Esse repertório de habilidades sociais educativas parentais, por sua vez, pode garantir às crianças os reforçadores de que necessitam sem, contudo, precisarem recorrer a comportamentos usualmente indicados por pais e professores como problemas de comportamento. 
Bolsoni-Silva, Salina, Versuti-Stoque e Rosin-Pinola (2008) ao comparar comportamentos dos pais e dos filhos (por meio de um roteiro de entrevista) em medidas de pré e pós-teste em intervenção durante o ano letivo, encontraram redução de indicativos de problemas de comportamento, como desobediência e agressividade, após o relato de aquisição de algumas habilidades sociais consideradas educativas parentais (HSE-P), como iniciar e manter conversação, expressar sentimento positivo e opiniões, além da consistência nas práticas educativas. Esses achados foram replicados numa versão concentrada da intervenção em um semestre letivo com mães/cuidadoras de pré-escolares com problemas externalizantes, cujos resultados parciais foram publicados por Bolsoni-Silva, Silveira e Ribeiro (2008), mostrando aumento de habilidades sociais das mães e das crianças, aumento de habilidades sociais educativas das mães/cuidadoras e redução dos problemas de comportamento das crianças, sugerindo relação entre essas variáveis, atentando para a existência de contingências entrelaçadas.

Boas (2007) investigou HSE-P (comunicação, expressividade e limites) em 43 mães separadas/divorciadas de crianças com idade entre 4 e 6 anos. $\mathrm{O}$ autor verificou que as crianças com problemas de comportamento tinham menos HSE-P que aquelas sem problemas, sinalizando que o divórcio pode trazer problemas para o desenvolvimento infantil se as mães tiverem dificuldades em interagir positivamente e consistentemente com seus filhos.

Leme (2008) partiu do relato de 40 mães (20 com filhos com problemas de comportamento e 20 com filhos sem problemas) sobre os comportamentos habilidosos e indicativos de problema dos filhos e investigou como as mães os "consequenciavam"; a autora encontrou que as mães de crianças com problemas de comportamento pouco davam atenção e elogiavam os comportamentos socialmente habilidosos dos filhos. Ao contrário, puniam os comportamentosproblema, relatando pouco repertório de HSE-P. No entanto, as mães das crianças habilidosas eram, de maneira geral, socialmente habilidosas para estabelecer limites e interagir nas diversas situações e também davam atenção e elogios aos comportamentos habilidosos dos filhos. O estudo indica uma relação funcional entre os comportamentos de mães e de crianças, seja quanto aos comportamentos habilidosos, seja quanto aos indicativos de problemas.

Considerando os pressupostos do behaviorismo radical e os anunciados pelo campo das habilidades sociais, acredita-se que essas habilidades sociais possam ser consideradas uma adjetivação de repertórios operantes, sobretudo verbais, pois são respostas "consequenciadas" por uma comunidade verbal e podem assumir funções tais como mando e tato. Tal reflexão poderia ser realizada para cada uma das habilidades sociais ora descritas, mas a título de 
exemplos, os comportamentos de fazer pedidos (HS) e de solicitar mudança de comportamento são "consequenciados" por membros de determinada cultura que podem atendê-los (reforçar) ou recusar-se a atendê-los (punir), mantendo-os ou suprimindo-os. Fazer pedidos poderia ser considerado um mando quando uma mãe pede ao filho que guarde seus brinquedos. Nesse caso, a educadora não guardou os brinquedos (comportamento não verbal) e sim solicitou ao filho que o fizesse. Quanto a solicitar mudança de comportamento que envolve várias HS (identificar o comportamento-problema, expressar sentimento negativo, informar comportamento alternativo e descrever possíveis consequências), há tanto a presença de mando como de tato, pois quando uma mãe solicita que a criança emita um comportamento alternativo, ela está dando uma ordem (mando), mas também ela descreve consequências naturais para os comportamentos (tato).

Esses são exemplos que remetem a outros conceitos: (a) o conceito de contingências entrelaçadas (Andery \& Sério, 2005) ao relacionar os comportamentos da mãe e do filho como influenciados mutuamente; (b) macrocontingências (Vargas, 2007) que são ações conjuntas de dois ou mais indivíduos; (c) comportamento social, que, para Skinner (1953/1993), é “O comportamento de duas ou mais pessoas, uma em relação à outra ou, em conjunto, em relação a um ambiente comum" (p. 17); (d) contingências sociais que não necessariamente produzem ou suscitam comportamentos eticamente desejáveis ou específicos de comportamento social, ou seja, comportamentos que trazem reforçadores para os indivíduos e para as pessoas com quem interagem, mas podem afetar a probabilidade deles quando são emitidos; o comportamento do indivíduo influencia as contingências sociais e vice-versa (Goldiamond, 1978/2002).

A partir do que foi discutido, entende-se habilidades sociais como uma "qualificação" que parece ter sido consolidada na prática cultural. Tal consolidação parece estar presente no contexto da comunidade científica, como "repertório socialmente habilidoso" (ou repertório socialmente inábil), ou "comportamento socialmente habilidoso" (ou comportamento inábil ou não habilidoso), como forma de "rotular", de "designar", de "nomear", de "adjetivar", de "qualificar" comportamentos que sejam ou não compatíveis com as funçôes sociais aceitas dentro das "normas", "regras" do nosso grupo social.

Nesse sentido, sendo as habilidades sociais uma "qualificação", elas possuiriam uma dimensão ético-moral, ou seja, elas remetem a um procedimento de escolha do que ensinar e do que não ensinar, do como ensinar, de que finalidades escolher quando nos interessa melhorar o repertório de HS 
das pessoas, sejam universitários, estudantes do ensino básico e fundamental, pais, etc.

Abib (2001a), preocupado em operacionalizar conceitos skinnerianos envolvidos com a ética, afirma que o sentimento é um pertinente guia de ética, isto é, se as pessoas, nas interações sociais, sentem-se bem, felizes, é sinal de que vivenciam mais contingências reforçadoras do que punitivas; ao contrário, sentimentos de tristeza e revolta sugerem a presença sobretudo de contingências aversivas. Para esse pesquisador, o bem da cultura, que implica sua sobrevivência, deve considerar tanto a probabilidade de respostas como o sentimento positivo associado, além de necessariamente garantir a diversidade cultural e reforçadores para todos os indivíduos, o que pode ser obtido pela criatividade e pelo autocontrole, ainda que implique um conceito bastante polêmico. Vandenberghe (2005) afirma, ao analisar especificamente a atividade do terapeuta, que suas práticas devem ajudar o cliente a reduzir os efeitos colaterais que vivencia desde as contingências aversivas envolvidas, deve promover independência e criatividade sem, contudo, prejudicar as demais pessoas.

Teoricamente, os conceitos de habilidades sociais e de competência social (Del Prette e Del Prette, 1999) remetem à ocorrência de comportamentos (socialmente habilidosos) que aumentariam a probabilidade de resolver problemas sem, contudo, prejudicar as demais pessoas, estando de acordo com os pressupostos da ética skinneriana, porque, em última análise, o que é bom para o indivíduo é aquilo que lhe traz reforçadores na atualidade e no futuro (Abib, 2001a). A taxonomia proposta por Del Prette e Del Prette (1999), quando testada empiricamente em diferentes populações, tem sido associada à obtenção de reforçadores, por exemplo, as professoras, ao serem socialmente habilidosas, produzem comportamentos de afeto em seus alunos (BolsoniSilva \& Castro, 2008); os pais, ao serem socialmente habilidosos, reduzem aversivos, na forma de agressividade e desobediência dos filhos, e aumentam reforçadores positivos ao conseguirem atenção e afeto destes (Bolsoni-Silva et alii, 2008).

Pretendeu-se, com a exposição de autores das habilidades sociais, da análise do comportamento e estudos empíricos, descrever possíveis relações funcionais entre problemas/transtornos e repertórios de habilidades sociais, de forma a exemplificar interaçôes sociais, contingências entrelaçadas e produtos agregados.

\section{Considerações finais}


Este texto privilegiou a apresentação e análise de resultados empíricos da área das habilidades sociais, buscando entendê-los funcionalmente na sua relação com práticas culturais. Depreende-se de tal análise que os comportamentos socialmente habilidosos estão associados à obtenção de reforçadores positivos e esquiva ou fuga, a negativos nas interaçóes sociais e, ainda, que novas pesquisas necessitem ser conduzidas. Os resultados até aqui gerados pelas pesquisas sugerem um caminho importante para favorecer o surgimento de novas práticas culturais que tornem as interações sociais mais equilibradas (Baum, 1999) e reforçadoras.

A literatura analisada indica compatibilidades entre habilidades sociais e análise do comportamento quanto aos princípios éticos de promoção de práticas culturais reforçadoras. Quanto ao método de pesquisa, encontram-se compatibilidades e dissensões: entende-se como compatível o delineamento de sujeito único para responder a perguntas de pesquisa na área de habilidades sociais (por exemplo, Carr \& Durang, 1995), mas se entende que o delineamento de grupo, pouco usual na análise do comportamento, ainda que não incompatível (Baum, 1999; Carrara, 2005) também seja importante e relevante para obter informaçôes acerca de práticas culturais e de metacontingências. Conclui-se que ambos os procedimentos de pesquisa produzem resultados por vias diferentes e complementares, sendo que o delineamento de grupo pode garantir validade externa no mapeamento de variáveis relevantes, as quais podem, em segundo momento, ser testadas experimentalmente, possibilitando, então, validação interna. De todo modo, os resultados até o momento produzidos, independentemente do delineamento, indicam a importância das habilidades sociais enquanto adjetivação de categorias de repertórios comportamentais relevantes para o favorecimento de interações sociais satisfatórias.

\section{Referências}

Abib, J. A. D. (1993). "A Psicologia é ciência?": ciência é articulação de discursos da Filosofia, da História da Ciência e da Psicologia. Psicologia: Teoria e Pesquisa, 9 (3), 465-486.

Abib, J. A. D. (2001a). Behaviorismo radical como pragmatismo na epistemologia. In: H. J. Guilhardi et alii (orgs.). Sobre Comportamento e Cognição. (v. 8, pp. 158-161). Santo André: Esetec.

Abib, J. A. D. (2001b). Teoria moral de Skinner e desenvolvimento humano. 
Psicologia: Reflexão e Crítica, 14, 107-117.

Abib, J. A. D. (2004). O que é comportamentalismo? In: M. Z. Brandão et alii (orgs.). Sobre Comportamento e Cognição. (v. 13, pp. 52-61). Santo André: Esetec.

Alvarenga, P. \& Piccinini, C. (2001). Práticas educativas maternas e problemas de comportamento em pré-escolares. Psicologia: Reflexão e Crítica, 14 (3), 449-460.

Andery, M. A. P. A; Micheletto, N. \& Sério, T. M. A. P. (2005). A análise de fenômenos sociais: esboçando uma proposta para a identificação de contingências entrelaçadas e metacontingências. Revista Brasileira de Análise do Comportamento, 2 (2), 149-165.

Bandeira, M. \& Quaglia, M. A. C. (2005). Habilidades sociais de estudantes universitários: identificação de situaçôes sociais significativas. Interação em Psicologia, 9 (1), 45-55.

Baum, W. M. (1999). Compreender o behaviorismo: ciência, comportamento e cultura. (M. T. A. Silva; M. A. Matos \& G. Y. Tomanari, Trad.). Porto Alegre: Artmed. (originalmente publicado em 1994).

Boas, A. C. V. B. V. (2007). Divórcio, habilidades sociais maternas e problemas de comportamento infantis. Dissertação de mestrado, Universidade Estadual Paulista, Bauru.

Boas, A. C. V. B. V.; Silveira, F. F. \& Bolsoni-Silva, A. T. (2005). Descrição de efeitos de um procedimento de intervenção em grupo com universitários: um estudo piloto. Interação em Psicologia, 9 (2), 323-332.

Bolsoni-Silva, A. T. \& Marturano, E. M. (2008). Habilidades sociais educativas parentais e problemas de comportamento: comparando pais e mães de préescolares. Aletheia (Ulbra), 27 (1), 126-138.

Bolsoni-Silva, A. T. \& Marturano, E. M. (2007). A qualidade da interação positiva e da consistência parental na sua relação com problemas de comportamento de pré-escolares. Revista Interamericana de Psicologia, 41 (3), 349-358.

Bolsoni-Silva, A. T. (2002). Habilidades sociais: breve análise da teoria e da prática à luz da análise do comportamento. Interação em Psicologia, 6, 233-242.

Bolsoni-Silva, A. T. \& Marturano, E. M. (2002). Práticas educativas e 
problemas de comportamento: uma análise à luz das habilidades sociais. Estudos de Psicologia, 7 (2), 227-235.

Bolsoni-Silva, A. T.; Brandão, A. S.; Versuti-Stoque, F. M. \& Rosin-Pinola, A. R. (2008). Avaliação de um programa de intervenção de habilidades sociais educativas parentais: um estudo piloto. Psicologia Ciência e Profissão, 28 (1), 18-33.

Bolsoni-Silva, A. T.; Del Prette, Z. A. P.; Del Prette, G.; Montanher, A. R. P.; Bandeira, M. \& Del Prette, A. (2006). Habilidades sociais no Brasil: uma análise dos estudos publicados em periódicos. In: M. Bandeira, Z. A. P. Del Prette \& A. Del Prette. Estudos sobre Habilidades Sociais e Relacionamento Interpessoal. (pp. 17-45). São Paulo: Casa do Psicólogo.

Bolsoni-Silva, A. T.; Silveira, F. F. \& Ribeiro, D. C. (2008). Avaliação dos efeitos de uma intervenção com cuidadoras: contribuições do treinamento em habilidades sociais. Revista Contextos Clínicos, 1 (1), 19-27.

Bolsoni-Silva, A. T.; de Paiva, M. M. \& Barbosa, C. G. (prelo). Problemas de comportamento de crianças/adolescentes e dificuldades de pais/cuidadores: um estudo de caracterização. Psicologia Clínica.

Bolsoni-Silva, A. T.; Marturano, E. M.; Loureiro, S. R. (2009). Construction and validation of the Brazilian questionário de respostas socialmente habilidosas segundo relato de professores (QRSH-PR). Spanish Journal of Psychology, 12 (1), 349-359.

Bolsoni-Silva, A. T. (2008). Roteiro de entrevista de habilidades sociais educativas parentais (RE-HSE-P): categorias e testagem preliminares. In: L. D. Weber (org.). Familia e desenvolvimento: visöes interdisciplinares. (pp. 145158). Curitiba: Juruá.

Caballo, V. E. (1996). O treinamento em habilidades sociais. In: V. E. Caballo (org.). Manual de técnicas de terapia e modificação do comportamento. (pp. 3-42). São Paulo: Santos Livraria Editora.

Caldarella, P. \& Merrell, K. W. (1997). Common dimensions of social skills of children and adolescents: a taxonomy of positive behaviors. School Psychology Review, 26 (2), 264-278.

Carr, E. G. \& Durang, V. M. (1985). Reducing behavior problem through functional communication training. Journal of Applied Behavior Analysis, 18, 111-126. 
Carrara, K. (2008). Bases conceituais revisitadas, implicações éticas permanentes e estratégias recentes em análise aplicada do comportamento. In: M. R. Cavalcante (org.). Avaliação e intervenção em análise do comportamento: aspectos de procedimentos. (pp. 1-14). São Paulo: Roca.

Carrara, K. (2005). Behaviorismo radical: crítica e metacrítica. São Paulo: Unesp.

Castro, A. B. \& Bolsoni-Silva, A. T. (2008). Habilidades sociais na educação: relação entre concepções e práticas docentes na educação infantil. In: Capellini, V. L. M. F. \& Manzoni, R. M. (orgs.). Politicas públicas, práticas pedagógicas e ensino-aprendizagem: diferentes olhares sobre o processo educacional. Bauru: Cultura Acadêmica.

Catania, A. C. (1999). Aprendizagem: comportamento, linguagem e cognição. (4. ed.). Tradução de Deisy das Graças de Souza et alii. Porto Alegre: Artes Médicas. (originalmente publicado em 1998).

Cia, F.; Pereira, C. S.; Del Prette, Z. A. P. \& Del Prette, A. (2006). Habilidades sociais parentais e o relacionamento entre pais e filho. Psicologia em Estudo, 11 (1), 73-81.

Del Prette, A. \& Del Prette, Z. A. P. (2003). No contexto da travessia para o ambiente de trabalho: treinamento de habilidades sociais com universitários. Estudo de Psicologia, 8 (3), 413-420.

Del Prette, A.; Del Prette, Z. \& Barreto, M. C. M. (1999). Habilidades sociales en la formación profesional del psicólogo: análisis de un programa de intervención. Psicología Conductual, 7 (1), 27-47.

Del Prette, Z. A. P. \& Del Prette, A. (1999). Psicologia das habilidades sociais: terapia e educação. Petrópolis: Vozes.

Del Prette, Z. A. P. \& Del Prette, A. (2006). Psicologia das habilidades sociais na infância. Petrópolis: Vozes.

Del Prette, Z. A. P. \& Del Prette, A. (2001). Psicologia das relaçôes interpessoais: vivências para o trabalho em grupo. Petrópolis: Vozes.

Del Prette, Z. A. P.; Del Prette, A.; Barreto, M. C. M.; Bandeira, M.; RiosSaldanã, M. R.; Ulian, A. L. A. O.; Gerk-Carneiro, E.; Falcone, E. M. O. \& Villa, M. B. (2004). Habilidades sociais de estudantes de Psicologia: um estudo multicêntrico. Psicologia: Reflexão e Crítica, 17 (3), 341-350. 
Evans, I. M. (1993). Constructional perspectives in clinical assessment. Psychological Assessment, 5 (3), 264-272.

Glenn, S. S. (1986). Metacontingencies in Walden Two. Behavior Analysis and Social Action, 5, 2-8.

Goldiamond (2002). Toward a constructional approach to social problems: ethical and constitucional issues raised by Applied Behavior Analysis. Behavior and Social Issues, 11 108-197 (originalmente publicado em 1974, Behaviorism, 2, 1-84).

Leme, V. R. B. (2008). Práticas educativas maternas e a sua relação com comportamentos habilidosos e problemas de comportamento de pré-escolares. Dissertação de mestrado, Universidade Estadual Paulista, Bauru.

Mayer, G. R. (1999). Constructive discipline for school personnel. Education and Treatment of Children, 22 (1), 36-54.

McFall, R. M. (1982). A review and reformulation of the concept of social skills. Behavioral Assesment, 4, 1-33.

Meyer, S. B. (2001). O conceito de análise funcional. In: M. Delliti, M. (org.). Sobre comportamento e cognição: a prática da análise do comportamento e da terapia cognitivo-comportamental (v. 2, pp. 29-34). Santo André: Esetec.

Patterson, G.; Reid, J. \& Dishion, T. (2002). Antisocial boys: comportamento antissocial. Santo André: Esetec.

Silveira, F. F. (2009). Descrição de habilidades terapêuticas a partir de intervenção em grupo com mães. Dissertação de mestrado, Universidade Estadual Paulista, Bauru.

Skinner, B. F. (1993). Sobre o behaviorismo. São Paulo: Cultrix. (originalmente publicado em 1974).

Skinner, B. F. (1984). Selection by consequences. The behavioral and brain sciences, 7 (4), 477-481.

Skinner, B. F. (1992) Verbal behavior. Cambridge: B. F. Skinner Foundation. (originalmente publicado em 1957).

Skinner, B. F. (1993). Ciência e comportamento humano. (8. ed.). São Paulo: Martins Fontes. (originalmente publicado em 1953).

Strapasson, B. A.; Carrara, K. \& Lopes Júnior, J. (2007). Consequências da 
interpretação funcional de termos psicológicos. Revista Brasileira de Terapia Comportamental e Cognitiva, 9 (2), 153-174.

Vandenberghe, L. (2005). Uma ética behaviorista radical para a terapia comportamental. Revista Brasileira de Terapia Comportamental e Cognitiva, 7 (1), 55-66.

Vargas, E. A. (2007). O comportamento verbal de B. F. Skinner: uma introdução. Revista Brasileira de Terapia Comportamental e Cognitiva, 9 (2), 227-239.

Zamignani, D. R. \& Meyer, S. B. (2007). Comportamento verbal no contexto clínico: contribuições metodológicas a partir da análise do comportamento. Revista Brasileira de Terapia Comportamental e Cognitiva, 9 (2), 241-259. 